\title{
Editorial: Cell biology in agriculture and food sciences
}

\author{
Bhumi Nath Tripathi ${ }^{1}$
}

Published online: 22 March 2016

(C) Springer-Verlag Wien 2016

Agricultural practices are considered to be the main source of food production to meet the requirement of the continuously increasing world population. Remarkable significance of agriculture for the livelihood of humankind has attracted the attention of scientists throughout world. A large number of studies are being conducted by researchers on various aspects of agriculture and food sciences. Present issue of the protoplasma is also focused on the cell biology of agriculture and food sciences based on an international conference on agriculture and biological sciences organized during July 25-28, 2015, at Beijing, China. The accepted manuscripts cover various aspects of agriculture and food sciences. Leaf crinkle disease (ULCD) is an economically significant widespread and devastating disease in legumes particularly urdbean (Vigna mungo). An overview of causal agent, vector, and host of leaf crinkle disease is given by Gautam et al. (2016). The comparative study of biochemical and ultrastructure features in senescing sugar beet (Beta vulgaris L.) leaves was carried out. The multitude of membrane impairments and lots of large vesicles-"crystals" appeared in senescing sugar beet (Romanova et al. 2016). Singh and Prasad (2016) have described the progress made in Agrobacterium-mediated transformation system in rice, maize, wheat, barley, sorghum, sugarcane, Brachypodium, millets, bioenergy and forage, and turf grasses. In addition, it also provides an overview of the

Bhumi Nath Tripathi

bhuminathtripathi@hotmail.com

1 Department of Biotechnology, Indira Gandhi National Tribal University, Amarkantak 484887, Madhya Pradesh, India genes that have been recently transferred to these graminaceous crops using Agrobacterium, bottlenecks in this technique and future possibilities for crop improvement. Further, Sharma et al. (2016) have demonstrated the comparative response of two contrasting genotypes (aluminum (Al) tolerant and $\mathrm{Al}$ sensitive) of chick pea (Cicer arietinum) against $\mathrm{Al}$ stress. They have concluded that rapid activation of catalase followed by citrate efflux improves $\mathrm{Al}$ tolerance in chick pea. Current trends of Bt crops and their fate on associated microbial community dynamics was reviewed by Singh and Dubey (2016). The severity of plant pathogen on crop productivity is well established. Rice bacterial blight, caused by Xanthomonas oryzae pv. oryzae (Xoo), is a severe disease of rice plants. The suppression of Xoo growth by a volatile terpene, $(S)$-limonene is reported by Lee et al. (2016a). Further, Lee et al. (2016b) have demonstrated the alleviation of salt stress in Brassica rapa L. ssp. perkinensis (Chinese cabbage) by Herbaspirillum sp. strain GW103 isolated from rhizosphere soil of Phragmites australis. Spoilage of stored grains and legumes is a severe agricultural problem. The outcome of the study conducted by Kedia et al. (2016) demonstrating antifungal and antiaflatoxigenic efficacy of Mentha spicata essential oil (EO) against toxigenic Aspergillus flavus strain LHP(C)-D6 in chickpea up to 12 months of storage could be an effective strategy to cope with decay of stored agricultural produce. Heat shock proteins (HSPs) exist extensively in eukaryotes and are conserved molecular chaperones with important contribution to plant's survival under environmental stresses. Overexpression of a Brassica campestris HSP70 in tobacco confers enhanced tolerance to heat stress (Wang et al. 2016). Based on the experiments on wild and gun 5 mutant of $A$. thaliana, Pattanayak and Tripathy (2016) have reported that the significance of levulinic acid (LA) in modulating chloroplast biogenesis at a desired phase of chloroplast development. 


\section{Compliance with ethical standards}

Conflict of interest The author declares that there is no conflict of interest.

\section{References}

Gautam NK, Kumar K, Prasad M (2016) Leaf crinkle disease in urdbean (Vigna mungo L. Hepper): an overview on causal agent, vector and host. Protoplasma. doi:10.1007/s00709-015-0933-z

Kedia A, Dwivedy AK, Jha DK, Dubey NK (2016) Efficacy of Mentha spicata essential oil in suppression of Aspergillus flavus and aflatoxin contamination in chickpea with particular emphasis to mode of antifungal action. Protoplasma. doi:10.1007/s00709-015-0871-9

Lee GW, Chung MS, Kang M, Chung BY, Lee SB (2016a) Direct suppression of a rice bacterial blight (Xanthomonas oryzae pv. oryzae) by monoterpene (S)-limonene. Protoplasma. doi:10.1007/s00709015-0904-4

Lee GW, Lee JC, Chae JC (2016b) Herbaspirillum sp. strain GW103 alleviates salt stress in Brassica rapa L. ssp. Pekinensis. Protoplasma. doi:10.1007/s00709-015-0872-8
Pattanayak GK, Tripathy (2016) Modulation of biosynthesis of photosynthetic pigments and light harvesting complex in wild type and gun5 mutant of arabidopsis thaliana during impaired chloroplast development. Protoplasma. doi:10.1007/s00709-016-0958-y

Romanova AK, Semenova GA, Ignatev AR, Novichkova NS, Fomina IR (2016) Biochemistry and cell ultrastructure changes during senescence of Beta vulgaris L. leaf. Protoplasma. doi:10.1007/s00709015-0923-1

Sharma M, Sharma V, Tripathi BN (2016) Rapid activation of catalase followed by citrate efflux effectively improves aluminum tolerance in the roots of chick pea (Cicer arietinum). Protoplasma. doi:10. 1007/s00709-015-0913-3

Singh AK, Dubey SK (2016) Current trends in Bt crops and their fate on associated microbial community dynamics: a review. Protoplasma. doi:10.1007/s00709-015-0903-5

Singh RK, Prasad M (2016) Advances in Agrobacterium tumefaciensmediated genetic transformation of graminaceous crops. Protoplasma. doi:10.1007/s00709-015-0905-3

Wang X, Yan B, Shi M, Zhou W, Zekira D, Wang H, Kai G (2016) Overexpression of a Brassica campestris HSP70 in tobacco confers enhanced tolerance to heat stress. Protoplasma. doi:10.1007/ s00709-015-0867-5 